\title{
FACES DA PRODUÇÃO PERIÓDICA NA CIÊNCIA DA INFORMAÇÃO: O PROCESSO DE LEGITIMAÇÃO CIENTÍFICA E SEUS COMPONENTES
}

\author{
ASPECTOS DE LA PRODUCCIÓN PERIÓDICA EN CIENCIA \\ DE LA INFORMACIÓN: EL PROCESO DE LEGITIMACIÓN \\ CIENTIIFICA Y SUS COMPONENTES
}

\begin{abstract}
Leilah Santiago Bufrem - santiagobufrem@gmail.com Doutora em Ciências da Comunicação pela Universidade de São Paulo (USP). Professora Visitante Sênior no Programa de Pós-Graduação em Ciência da Informação da Universidade Federal de Pernambuco (UFPE)
\end{abstract}

\section{RESUMO}

Introdução: Apresenta resultados de pesquisa sobre a produção científica registrada em Ciência da Informação, a partir de dados empíricos obtidos em pesquisa bibliométrica sobre um corpus da literatura da área no Brasil, produzido por grupo de pesquisadores representativos, no período de 1993 a 2013, destacando as relações apresentadas no processo de consagração e de legitimação e cotejando-as com os aspectos teóricos relativos aos processos de produção e reprodução na literatura científica, assim como à distinção atribuída pela comunidade a pesquisadores e instituições.

Objetivo: Analisa, partindo de configurações bibliométricas, as características e as relações que essa produção apresenta e como se destacam seus componentes.

Metodologia: Identifica os artigos científicos dos 15 pesquisadores com a produção mais expressiva no período de 1993 a 2013, partindo de um levantamento bibliométrico dos periódicos vigentes, indexados na Base de Dados Referenciais de Artigos de Periódicos de Ciência da Informação (Brapci). Analisa os artigos científicos, identificando seus temas e relacionando seus autores às instituições e às posições que representam, para posterior organização numa planilha eletrônica, geradora dos gráficos utilizados. Com a mesma estratégia, incorpora a filiação dos autores e suas posições como pesquisadores junto ao CNPq. Completa a identificação com a busca de informações sobre a situação da pósgraduação em $\mathrm{Cl}$ no Brasil e das posições dos grupos de pesquisa e dos pesquisadores para uma visualização sincrônica do contexto. 
Resultados: Destaca que um terço dos autores faz parte do rol de pesquisadores do CNPq e que as instituições de maior destaque na área da $\mathrm{Cl}$, cujos programas são os mais antigos e contam com doutorado, abrigam a maioria dos pesquisadores CNPq.

Conclusões: Observa que a legitimação e a distinção decorrem do tempo de poder, ou seja, da permanência em situação capaz de organizar e estruturar condições de produção mais estáveis e, portanto, com melhores oportunidades de sucesso. As reflexões sobre os três aspectos críticos do processo de pesquisa científica, a produção, a reprodução e a distinção, apresentam singularidades que ilustram as convergências para a concretude do processo legitimador das instâncias de consagração na comunidade de experiências desse campo de produção científica.

Palavras-chaves: Produção científica. Reprodução. Distinção. Ciência da Informação.

\section{INTRODUÇÃO}

Ao elevarmos como pressuposto o princípio de que a análise crítica da produção científica é uma forma de construção, temos consciência de que essa postura exige vigilância e responsabilidade. Identificada com reflexões intencionalmente voltadas aos objetos da ciência, às propostas a eles relacionadas e aos modos de atingir objetivos, essa forma de crítica é um desafio para quem a produz, assim como para a produção que dela resulta.

Os produtos do conhecimento, marcados pelo dinamismo das relações entre as práticas de produção e comunicação científica de um campo de saber instituído e o seu potencial de representatividade, desdobram-se no cotidiano da ciência. Eventos, associações, programas e periódicos científicos, sistemas de avaliação, editais de bolsas, critérios e indicadores, normas e regulamentos, contribuem para reforçar as estruturas formais e a institucionalização social da ciência. Impõe-se, nessa conjuntura, a observação das evidências e relações presentes nesse processo, assim como a análise da produção registrada em meios de divulgação.

Das reflexões críticas sobre a experiência individual acumulada de um sujeito pesquisador, resultam posições que refletem sua conduta acadêmica e profissional. Assim, este artigo destaca reflexões decorrentes de nossa compreensão sobre a produção científica registrada em Ciência da Informação, confrontadas com resultados empíricos obtidos em pesquisa bibliométrica.

Essa posição supõe a eleição de concepções teóricas que permitam analisar e interpretar os elementos críticos e as sugestões para as transformações do 
campo. Nestas reflexões sobre a pesquisa na pós-graduação em Ciência da Informação $(\mathrm{Cl})$ no Brasil, relacionamos três categorias de análise, identificadas com os processos de produção, reprodução e distinção, que aqui serão tomadas como suporte à análise de posições empíricas representativas do capital científico e das hierarquias temporalmente dominantes de sujeitos pesquisadores em seus graus diversos de distinção. (BOURDIEU, 2013, p. 63).

As experiências e observações pessoais vividas em nosso cotidiano relacional com a pesquisa, tanto na vertente da produção científica, quanto no fazer docente nas áreas da $\mathrm{Cl}$ e da Educação, resultaram em reflexões sobre a experiência acumulada e estas, por sua vez, em posição crítica e autocrítica sobre a realidade aqui descrita, na qual atuamos e a qual estamos permanentemente transformando. A eleição de concepções teóricas em prol dessa análise e interpretação pode fortalecer posturas e sugestões para a transformação desejada.

A modo de tese, construída no decorrer desses anos de reflexão sobre a pesquisa, docência e atuação correlata na formação de pesquisadores, na avaliação e na crítica de processos e produtos, este texto foi originado das reflexões realizadas quando da palestra ao Programa de Pós-Graduação em Ciência da Informação da Universidade Federal da Paraíba. Esperamos que ele seja objeto do interesse e aproveitamento dos leitores como incentivo à produção institucionalizada, pelo que insistimos no valor da experiência crítica à prática da pesquisa científica cotidianamente vivida.

A partir do olhar do observador, seja participante do sistema de avaliação, seja intelectual dotado de autoridade e condições críticas no exercício analítico, delineia-se o processo de produção, reprodução, legitimação e distinção no campo científico. Esse processo é concretizado pelas instâncias de consagração na comunidade de pesquisadores da $\mathrm{Cl}$, pelo que inicialmente se destacam os aspectos relacionados à produção científica e a seguir as características do que se pode reconhecer como reprodução, para então esclarecer os aspectos relativos à concretização e às formas da distinção adquirida pelo pesquisador na e pela comunidade científica.

O que caracteriza esse processo, que relações ele apresenta e como atuam seus componentes são questões desafiantes, especialmente se levada em conta a crescente expansão dos elementos competitivos e o consequente arrebatamento 
que vêm exercendo sobre os acadêmicos e pesquisadores, resultando em formas de reprodução e distinção social no campo científico.

Responder a essas questões, procurando captar o processo de legitimação concretizado pelas instâncias de consagração na comunidade de experiências do campo de produção científica na área de $\mathrm{Cl}$, a fim de esclarecer aspectos relativos à validade e às consequências dessa forma de distinção adquirida junto à comunidade, é o propósito deste artigo. Com esse intento, buscamos contemplar a caracterização de um recorte da produção científica na área no Brasil, analisando as possíveis relações apresentadas no processo de consagração e de legitimação de um grupo de pesquisadores na comunidade científica, observando os aspectos relativos à distinção atribuída pela comunidade científica a pesquisadores e instituições.

Tentamos, por um lado, perceber a dinâmica das relações entre esta prática de produção e comunicação científica na área e o seu potencial de representatividade e, por outro, a sua efetividade em relação ao processo de produção e reprodução de conhecimentos científicos e seus consequentes desdobramentos no campo. Essas perspectivas decorrem da função que desempenham as instâncias de consagração, tanto em relação ao conjunto de autores que constituem o grupo de elite, quanto ao público a que se destinam as produções científicas filtradas pelos seus mecanismos de seleção. Assim dimensionadas, constituíram-se as reflexões sobre três aspectos críticos do processo de pesquisa científica: a produção, a reprodução e a distinção, realidades que apresentam convergências para sua concretude.

\section{OS SENTIDOS DA PRODUÇÃO CIENTÍFICA}

Entre tantas definições encontradas na literatura, consideramos como produção científica o conjunto de publicações gerado durante a realização e após o término das pesquisas, por um pesquisador, grupo, instituição ou país, nas diferentes áreas e registrado em diferentes suportes. (OLIVEIRA; GRACIO, 2009).

A reflexão sobre a produção científica, decorrente de leituras e de experiência pessoal, implica em quatro categorias de análise: a concretude de seus resultados; a 
Faces da produção periódica na Ciência da Informação: o processo de legitimação científica e seus componentes

diversidade de sua natureza; os contextos e dimensões que a identificam e os sentidos advindos das relações espaciotemporais. Percebe-se, desse modo que:

a) ela ocorre em contextos concretos, nos quais pesquisadores realizam práticas e utilizam seus referenciais para dar sentido aos problemas de pesquisa, que nem sempre se ajustam a suas ideias e referenciais prévios;

b) fatores de natureza diversa influenciam a pesquisa científica, tais como as vivências prévias dos sujeitos, a natureza especifica do conhecimento ou domínio, os tipos de problemas e objetos construídos e as aptidões individuais, elementos fundamentais para produção do conhecimento novo;

c) as ideias dos pesquisadores apresentam-se em contextos lógicos, teóricos, sociológicos e psicológicos diferenciados, podendo oscilar entre níveis mais ou menos elaborados de pesquisa, conforme o objeto, os objetivos e a situação. A progressão de ideias pode ser revelada em estudos diacrônicos como tendencial, mas não tem caráter determinante.

d) as relações espaciais e temporais dão sentido à prática da pesquisa científica.

Esses sentidos permitem ao pesquisador incorporar aspectos de sua formação científica, marcados pelo espaço e tempo vividos, representando-os na sua prática de pesquisa, no seu entendimento dos conteúdos pesquisados e dos métodos que utiliza para dominar aspectos teóricos e práticos de seu campo. Desse modo, a tradição científica vem estabelecendo condicionantes institucionais para a transmissão dos conhecimentos produzidos.

Iniciada na década de 1970, a produção periódica em Cl no Brasil é uma das mais evidentes manifestações desse processo, como escoadouro dos resultados de pesquisas dos primeiros cursos de pós-graduação no país, no Instituto Brasileiro de Bibliografia e Documentação (IBBD), que viria a se transformar em Instituto Brasileiro em Informação Científica e Tecnológica (Ibict).

O Instituto Brasileiro de Bibliografia e Documentação (IBBD), criado por meio do decreto no 35.124, de 27 de fevereiro de 1954, foi transformado no atual Instituto Brasileiro de Informação em Ciência e Tecnologia (Ibict), por meio da Resolução no 20/76, de 25 de março de 1976. Portanto, ao tratar do lbict, é impossível deixar de fazer uma alusão ao IBBD, órgão que the deu origem e, como tal, possui enormes ligações históricas. (CUNHA, 2005). 
A partir da criação da Associação Nacional de Pesquisa e Pós-Graduação em Ciência da Informação (Ancib), em 1989, sociedade científica representante da comunidade de pesquisadores da área, ampliou-se o ambiente para a produção científica em seus diversos gêneros e o desenvolvimento de atividades que representam as relações de forças no campo científico. Conforme Barreto (2009, p. 11)

[...] as condições históricas de sua criação esclarecem muito do que hoje acontece com toda a reflexão de pesquisa da área, seu ensino na pós-graduação e o conviver de seus profissionais numa associação de ensino e pesquisa como a Associação Nacional de Pesquisa e Pós-Graduação em Ciência da Informação.

Revigoraram-se os modos de produção, repercutindo significativamente no conhecimento registrado da área, de modo a compor um dinâmico cenário de práticas relacionadas aos processos de reprodução e distinção, produzindo desdobramentos no campo. Esses desdobramentos legitimadores de sujeitos, domínios e práticas, instituíram gradativamente uma cultura permeada por valores de troca (BOURDIEU, 1992), tornando seus produtos parte do mercado dos bens simbólicos no campo científico.

Esses bens, se por um lado mobilizam o campo de produção em que se estabelece o confronto entre atores, instituições, programas, critérios e indicadores, contribuindo para escolhas e aspirações por posições hegemônicas, por outro, conjugam-se como bens de troca, cujo valor depende das relações entre os sujeitos. Essas, por sua vez, se concretizam por meio de convênios, coautorias, programas especiais como mestrados ou doutorados interinstitucionais (Minter e Dinter) ${ }^{1}$, visitas, convites para participações especiais, como manifestação do prestígio atribuído a determinados atores, ou elementos de distinção, distribuídos conforme seus méritos e posições de poder, representando às vezes relações assimétricas.

No Brasil, a área de $\mathrm{Cl}$ tem revelado atividade profícua e constante nos últimos vinte anos, institucionalizando-se social e cognitivamente, conforme o conceito de Whitley (1974, p. 71), como resultado de ações e significados em prol da

\footnotetext{
${ }^{1}$ Os projetos de Mestrado e Doutorado Interinstitucional têm como objetivo permitir a utilização da competência de programas de pós-graduação avaliados com nota igual ou superior a 5 e reconhecidos pelo CNE/MEC para, com base em parceria ou cooperação interinstitucional, viabilizar a formação de mestres e doutores fora dos centros/regiões mais consolidados de ensino e pesquisa.
}

Inf. Inf., Londrina, v. 19, n. 3, p. 01 - 29, set./dez. 2014. http:www.uel.br/revistas/informacao/ 
coerência e da organização de ações e percepções, assim como de articulação das ideias constitutivas da área. Assim, se por um lado o conhecimento produzido tem sido reconhecido pelos pares e instituições, por outro, as revistas científicas traduzem a consolidação de áreas, linhas, grupos e projetos de pesquisa, elementos constitutivos de um campo científico. Mas o campo não é pacífico, como alerta Bourdieu (1983). Ao considerá-lo como um campo social como outro qualquer, o autor o define como um espaço de produção da ciência, cujas propriedades dependem das posições definidas objetivamente em sua existência e nas determinações que elas impõem aos seus ocupantes, agentes ou instituições, por sua situação e posições ocupadas.

Ao auferir essas relações, atribuímos significado, avaliamos vestígios e relatos de pesquisa, percebemos transformações, criticamos progresso e declínio, e empregamos critérios, indicadores, empatia, julgamento e seleções. A procura de modelos, padrões ou indicadores de avaliação, decorrente desses processos de produção e validação da ciência, passou a se constituir em preocupação e objeto de estudo e de pesquisas, especialmente nas últimas décadas, em decorrência do grande crescimento documental que tornou, de certa forma, indispensável o uso de instrumentos para avaliação da ciência publicada, particularmente em instituições de pesquisas e pesquisadores.

Esses pesquisadores, vinculados a um determinado campo científico, exercem seu trabalho e suas escolhas científicas, selecionando teorias, metodologias, enfoques, estratégias e técnicas, constituindo uma espécie de comunidade em que compartilham valores, crenças e práticas que Ihes são comuns, nesse palco de relações de força, disputas e estratégias com vistas aos interesses específicos dos participantes, tais como publicar, participar de cursos e eventos científicos, bancas e comissões de estudos e concursos e demais atividades ou tipos de produção acadêmica. A pluralidade dos princípios concorrentes de hierarquização faz com que, assim como o campo de poder no seu conjunto, cada campo ofereça prestígio intelectual e satisfação pessoal correspondente. (BOURDIEU, 2013, p. 153).

Portanto, o campo é espaço de luta, de afirmação, de contradições e confrontos, cuja conjuntura é marcada pelas relações de poder e pelos problemas científicos que mobilizam essas formas de relacionamento, pois são momentos de 
contraposição ativa e consciente em que os pesquisadores atuam. Por meio do habitus, uma forma de disposição à determinada prática de grupo ou classe (BOURDIEU 1989, p. 386-387), são interiorizadas estruturas objetivas das suas condições de classe ou de grupo sociais que geram estratégias, respostas ou proposições objetivas ou subjetivas para a resolução de problemas. Segundo Bourdieu (1989, p. 386-387), as práticas por meio das quais se afirma a tendência dos dominantes de se perpetuarem são diferenciadas e organizam-se objetivamente, sem ter sido explicitamente concebidas e postas com relação a este fim. Como formas de perpetuação e domínio, as práticas de reprodução reforçam com seu poder simbólico as relações de força na sociedade.

\section{OS SENTIDOS DA REPRODUÇÃO CIENTÍFICA}

O traço fundamental e essencial da teoria marxista do conhecimento, analisada por Prado Junior (2001), é a natureza "construtiva" do ato de conhecer, significando que o conhecimento resulta de construção efetuada pelo pensamento e suas operações; e consiste numa "representação" mental do concreto. Isso significa que é uma representação "elaborada a partir da percepção e intuição". O conceito de "representação", entretanto, não se identifica com o de reprodução, decalque ou outra forma da transposição de algo, da realidade para o pensamento.

Assim, pode-se inferir que a produção científica, como resultado desse processo de construção e representação difere do que se denomina reprodução. A produção resulta do conhecimento original e primário, enquanto que a reprodução se expressa como uma cópia do que se produziu.

Considerando-se que certas posições e práticas contribuem para a reprodução do capital cultural ou científico produzido quando se trata de valor científico, a primeira estratégia dos grupos dominantes tem por objetivo manter e reproduzir a ordem vigente, à qual se vinculam. Eles se imbuem das ações de ditar e definir o que é ou não legitimamente científico, através de sua autoridade já estabelecida. Suas estratégias visam à conservação e à reprodução. E aos iniciantes, que se acomodam ao grupo dominante e às práticas por estes estabelecidas, caracterizadas como estratégias de sucessão, restam avanços científicos dentro dos limites permitidos, suficientes para que possam substituir a 
geração anterior (BOURDIEU, 1983). Seria um modo de reprodução de valores e posições no campo.

Surgem, nesse contexto, os signos da reprodução, representados pelo reforço desnecessário de certas ideias, pela comunicação científica fatiada, pela redundância dos elementos discursivos, pelas repetições e reiterações. Nesse contexto, reitera-se o poder dos eleitos, reproduzindo-se relações de força, nem sempre simétricas. Repetem-se discursos, em seus formatos e argumentos e a comunicação redundante engendra produtos e reproduz posições e valores. Reprodução de conhecimento, de status, de poder, de registros, de originais, de modelos, de sistema são formas de manifestação desse fenômeno.

As questões relativas à reprodução também podem ser interpretadas por meio das contribuições de G. Lukács (Para uma Ontologia do ser social), de L. Althusser (Sobre a Reprodução e Ensaio sobre os Aparelhos Ideológicos de Estado) e de Bourdieu e Passeron (A Reprodução - Elementos para uma teoria do sistema de ensino). Lukács analisa o problema sob o enfoque ontológico, da auto explicitação categorial humana, tanto no polo do gênero, quanto no polo individual. Quanto a Althusser, destaca o papel do aparelho escolar para a reprodução das relações de poder.

Já sob o ponto de vista de Bourdieu e Passeron (2008, p. 32), a análise da reprodução origina-se na existência de uma força social simbólica, entendida como uma transmissão deliberada. Enquanto poder de violência simbólica é exercido numa relação de comunicação como inculcação de um arbitrário.

Assim como no sistema escolar, as relações de produção no campo científico contribuem para a conservação das situações estabelecidas, produzindo-se uma correspondência entre as instituições e as práticas de produção e comunicação científica, por um lado e os interesses de grupos ou classes situadas em posição dominante entre as relações de força, por outro. Reproduz-se, assim, a estrutura de distribuição do capital científico entre esses grupos ou classes e os valores classificam-se conforme as leis do mercado, convertendo-se em capital cultural. Reproduz-se o poder entre diferentes autores, grupos, produções e eventos.

O capital universitário, conforme Bourdieu (2013, p. 115), é obtido e mantido "por meio da ocupação de posições que permitem dominar outras posições e seus ocupantes", controlando-se as instâncias que asseguram aos detentores uma 
"autoridade estatutária". Constituem-se práticas mais ou menos determinantes segundo os tipos de formação social, pelas quais se acha assegurada a reprodução das relações de força entre classes, função de legitimação da ordem social e que contribui para a perpetuação da estrutura das relações de classe. (BOURDIEU; PASSERON, 2008, p. 244). As causas da acumulação do capital científico e dos desequilíbrios de poder passam a ser percebidas menos por motivos econômicos do que culturais e as formas institucionalizadas de produção científica contribuem ativamente para produzir e reproduzir as desigualdades no cotidiano. $\mathrm{O}$ que se revela no conjunto de indícios a partir dos quadros descritivos e de citações de autores não só permite o estabelecimento dos rankings de pesquisadores e de departamentos ou instituições, como também a elaboração de comparações com variáveis determinantes da qualidade acadêmica, como, por exemplo, medidas de produção científica, períodos de concentração de poder e outros índices de qualidade e de produção e reprodução acadêmica dos diferentes pesquisadores. Há também a possibilidade de comparar resultados entre si para que se possam inferir predominâncias, lacunas ou tendências temáticas na produção científica.

Percebem-se, com o auxílio desses estudos sobre o cotidiano da produção científica, modos de reprodução inerentes aos processos de conhecimento, ao status, ao poder e suas relações, aos originais, aos temas, formatos e modos de pesquisar. Destacam-se, também, em meio às relações de poder no cenário científico, formas de distinção passíveis de uma análise mais acurada em estudo específico sobre o tema.

\section{FORMAS DE DISTINÇÃO}

A acumulação e a perpetuação de poder na mão de determinados grupos acomodam posições de força antagônica, mas simultaneamente fazem surgir formas de distinção acadêmica. Distinguem-se atores ou autores, temas e modalidades de fazer ciência, práticas científicas, correntes teóricas, instituições acadêmicas ou científicas. Revela-se até uma ética nas relações de poder, com características próprias para um determinado tempo e lugar. Bourdieu (1989, p. 8) compreende que nessa inserção espacial em determinados campos sociais, a posse de grandezas de certos capitais e o habitus de cada ator social condicionam sua posição hierárquica. 
Faces da produção periódica na Ciência da Informação: o processo de legitimação científica e seus componentes

Nessa luta social, para ocupar um espaço é necessário que o ator conheça as regras do jogo dentro do campo e que esteja disposto a jogar. Analogamente, isso ocorre em relação ao uso de determinados bens ou ao comportamento social ou acadêmico, pois como argumenta Bourdieu, "[...] o mesmo comportamento ou o mesmo bem pode parecer distinto para um, pretensioso ou ostentatório para outro e vulgar para um terceiro" (1996, p. 22).

Para que se entenda o que determina a posição espacial no campo social, devem-se reconhecer os princípios de diferenciação que condicionam a ocupação do espaço. Assim como nas sociedades desenvolvidas os fatores de distinção são as posses de capital econômico e de capital cultural, no ambiente acadêmico, os sujeitos ocupam espaços mais próximos quanto mais similares forem a quantidade e a espécie de capitais que detiverem. Dessa forma, o capital cultural ou científico gera internalizações de habitus que diferenciam os espaços a serem ocupados pelos homens e, portanto, os distinguem, como argumenta Bourdieu:

Sem dúvida, os agentes constroem a realidade social; sem dúvida, entram em lutas e relações visando a impor sua visão, mas eles fazem sempre com pontos de vista, interesses e referenciais determinados pela posição que ocupam no mesmo mundo que pretendem transformar ou conservar $(1989$, p. 8).

Produz-se a distinção em dimensões de natureza cognoscitiva, ética, política, científica, cultural e econômica. A produção científica, constituída especialmente por livros, comunicações e periódicos científicos, não somente representa o que foi elaborado como resultado das pesquisas realizadas, mas principalmente estabelece grande parte das condições materiais, tanto para a crítica e a produção de novos conhecimentos, quanto para a sua reprodução. Os textos resultantes dessa prática, produzidos em ambiente de afirmação e contradição, têm servido por excelência para o processo ensino/aprendizagem nas salas de aula da graduação e pósgraduação e frequentemente têm definido a sua legitimidade pelos pares e instituições em processo de legitimação científica. Esse processo configura núcleos e instâncias de poder, resultantes de mecanismos de consagração, explicitados por Bourdieu (2013, p. 123). Destaca-se uma perspectiva burocrática para substituir os modelos de avaliação, distinguem-se e consagram-se os pesquisadores, os grupos, as instituições e seus produtos, em níveis hierárquicos, indicam-se as melhores 
Faces da produção periódica na Ciência da Informação: o processo de legitimação científica e seus componentes

instituições e os melhores eventos, os quais passam a ser respeitados e durante um período de manutenção do status permanecem no cume, sendo considerados pela crítica.

Desde Kant, os julgamentos que têm levado à consagração tiveram seu interesse largamente ampliado. O juízo e o julgamento são discutidos na Crítica da Faculdade do Juízo (2008) e a preocupação do autor tem a ver com a questão da crítica e do próprio poder de julgar. A indagação básica de Kant recai sobre a existência ou não de algum valor universal que conceitue o belo e que reivindique sua confirmação universal, sem a qual seríamos obrigados a admitir que todo objeto que julgamos como sendo belo é uma valoração subjetiva. Dai decorre que a observação atenta e valorativa daquele objeto, somada aos diferentes referenciais das pessoas que o apreciaram, resultaria em diferentes opiniões críticas, o que levou Kant a afirmar que sobre gosto se discute, em prol da reivindicação para tornar universal um juízo subjetivo.

Ao aplicarmos o mesmo tipo de preocupação aos julgamentos das produções científicas, destacam-se as questões relacionadas à subjetividade, também inerente a esse tipo de crítica. Analogamente, procuramos neutralizar as possibilidades e limitações das faculdades subjetivas que agem sob princípios estabelecidos individualmente e que pertencem ao âmbito do pensamento. Uma mesma produção intelectual, apreciada por especialistas de áreas ou linhas de pesquisa diversas, intelectuais de diversos campos de atuação e instituições, pode determinar avaliações e julgamentos diversos.

$\mathrm{Na}$ área da produção científica, são construídos historicamente princípios, critérios, padrões, normas e indicadores com o intuito de orientar julgamentos resultantes das análises críticas sobre os resultados das pesquisas científicas. Eles compõem uma possibilidade de enfrentamento a essa diversidade de olhares e movimentos, envolvendo um exercício persuasivo de convencimento de um sujeito ou grupo de sujeitos, por outro ou outros, supostamente detentores de conhecimentos sobre os fundamentos científicos e metodológicos daquele campo de conhecimento em que atuam. E, dessa forma, aproximam-se do que se espera seja um valor universal. Assim como os sujeitos têm em comum um princípio de avaliação moral livre que determina a avaliação estética e, portanto, julga o belo 
como universal, assim procedem em relação ao que se pretende seja um valor científico.

Configura-se, nesse processo, uma dupla dimensão: a política e a epistemológica. As escolhas do objeto, do método empregado, das instituições às quais um cientista se filia, de instrumentos, técnicas e recursos utilizados, não são escolhas fortuitas ou meramente científicas, mas estão permeadas pelos efeitos de uma luta de poder neste campo específico, por prestígio e reconhecimento dos pares, que são, também, concorrentes no campo.

As práticas de produção e comunicação científica, portanto, estão organizadas a partir de comportamentos que pressupõem um conjunto de competências e normas, além de uma espécie de controle regulado dessa produção. Ao final desse processo, os procedimentos de verificação permitem o reconhecimento e a distinção social dos pesquisadores e dos conhecimentos por eles produzidos. O grau de reconhecimento e consagração a ser concedido pelos pares depende, portanto, das relações de uma estrutura inteira que se interpõe entre o produtor autor do texto científico - tese, dissertação, monografia, artigo ou comunicação - e suas ambições mais legítimas.

Este processo, iniciado no momento da criação da obra, compõe-se de fases críticas para seu autor, como defesa, submissão de artigos, de projetos a órgãos de fomento, expressando-se por etapas de seleção, até que ele alcance o êxito no campo científico onde atua.

A questão merece reflexões sobre as relações de poder existentes no campo, pois, embora os autores e instituições mantenham com este poder relações essenciais, nem sempre dominam plenamente o conhecimento das novas variáveis e forças que interagem na conjuntura em que atuam.

Assim, definem-se os elementos de distinção, inerentes ao papel dos consultores e pareceristas, como partícipes dessa estrutura acadêmica, e cuja autoridade cultural é reconhecida, tanto pela intimidade que mantém com o conteúdo, a linguagem científica e o estilo acadêmico, quanto pela sua própria produção. Sua atuação algumas vezes se realiza à maneira de perito público, avaliador ou até juiz. Sua autoridade chega a ser tão indiscutível que muitos autores levam em consideração, ao escrever, o provável leitor que irá avaliar sua obra. A 
Faces da produção periódica na Ciência da Informação: o processo de legitimação científica e seus componentes

obra, artigo, tese, dissertação ou comunicação, portanto, seria realizada na medida certa para sua consagração.

É possível identificar os atores em redes e distingui-los pelo exercício da dominância, por exemplo, no sentido atribuído ao termo pela teoria de Bourdieu, o que se faz graças a Análise de Redes Sociais (ARS) e às medidas de centralidade da ARS, verificáveis estatisticamente. Assim, os pesquisadores de destaque nas medidas de grau nodal, centralidade de proximidade ou de intermediação têm sido considerados os atores dominantes (BOURDIEU, 1983) da rede, graças à posição de destaque no campo de relações objetivas em que atuam, regulando o direito de entrada em grupos especiais no campo, tais como grupos de pesquisa, instituições e academias.

Outra forma de estabelecer posições hierárquicas é analisada por Murguia e Sales (2012) em relação às áreas e subáreas do conhecimento estabelecidas nas tabelas do CNPQ, definidas por eles como aparatos de conhecimento e poder. $\mathrm{O}$ trabalho é uma primeira reflexão, na qual entendem a organização do conhecimento sob a ótica de Foucault, visando a analisar um instrumento que guia a organização do conhecimento nos campos acadêmico e de pesquisa no Brasil, ou seja, a tabela de áreas do CNPq. Para os autores a posição da $\mathrm{Cl}$ nessa tabela foi produto de reflexões nacionais e internacionais nos anos de 1980, atribuindo a ela uma posição hierárquica superior e abrangente em relação à Teoria da Informação, à Biblioteconomia e à Arquivologia, o que conduziu à demanda para promover a interdisciplinaridade e suas consequências.

Portanto, o valor relativo desta reflexão e dos seus resultados reside nas contribuições que possam oferecer às políticas de produção e comunicação científicas. A crítica sobre a prática concreta dessas atividades poderá identificar situações e variáveis passíveis de serem transferidas a outras áreas e contextos. Poderá também contribuir para o conhecimento e as necessárias transformações da prática, assim como para retirar dos desdobramentos concretos do processo, aqueles elementos que poderão sugerir soluções para outras realidades.

Essa conjuntura mostra uma luta expressiva pelas posições na rede analisada, nos grupos de pesquisa e nos mapeamentos e configurações resultantes de estudos métricos, expressando graficamente as lutas e disputas, nas quais os atores se utilizam de estratégias pautadas pela aceitação e pela adequação à 
hierarquia presente nesse contexto, com propósitos de acumular capital científico e, consequentemente, galgar e/ou manter posições de destaque.

Podem-se analisar os conceitos para mapear o processo resultante de conflitos e contradições entre grupos de pesquisa, interesses e discursos, assim como as orientações e tendências de reprodução, distinções ou transformações.

A distinção é, desse modo, um estado diferencial e decorrente da aprovação pelos pares e instituições, diretamente associado à possibilidade de aumento de ampliação de trabalhos publicados pelo intelectual ou pelo grupo.

Ao concordar com Bourdieu, para quem a sociologia é uma ciência que incomoda, já que pretende interpretar os fenômenos sociais de maneira crítica, adotamos a postura do sociólogo, mais especificamente, a maneira pela qual ele interpreta a formação do gosto para colocar também sob o olhar crítico os consensos e dissensos instituídos em relação à produção científica. Ao reconhecermos que a comunidade científica coloca os pesquisadores em estado de concorrência e que deste modo a competição tem estimulado a produção de conhecimentos, resta-nos considerar que como consequência da competição, os conhecimentos gerados precisam ser atestados: somente sobrevivem e se expandem os resultados que resistem à crítica coletiva. (SANTOS, 2003).

\section{TRAJETÓRIA DO ESTUDO}

As pesquisas métricas têm sido utilizadas para indicar as relações entre produção, credenciamento em programas de pós-graduação, grupos de pesquisa, bolsas de instituição de fomento, como do CNPq, ratificando que os pesquisadores "mais produtivos" da área se encontram predominantemente concentrados em espaços formais de produção do conhecimento. Assim, como parte de uma pesquisa mais ampla sobre a produção científica registrada em periódicos brasileiros, percorreu-se inicialmente um procedimento de reconhecimento dessa produção.

A primeira fase do estudo abrangeu o reconhecimento dos periódicos vigentes indexados na Base de Dados Referenciais de Artigos de Periódicos de Ciência da Informação - Brapci ${ }^{2}$, e averiguadas as suas qualificações, segundo o

\footnotetext{
${ }^{2}$ A Brapci é resultado de um projeto de pesquisa acadêmica com o intuito de facilitar a pesquisa de documentos e artigos da área. Hoje, constitui-se no mais completo repositório da produção científica

Inf. Inf., Londrina, v. 19, n. 3, p. 01 - 29, set./dez. 2014. http:www.uel.br/revistas/informacao/ 
sistema de consulta de classificação de periódicos WEBQUALIS ${ }^{3}$. A seguir foram identificados os pesquisadores com maior número de artigos nos periódicos em $\mathrm{Cl}$ no período de 1993 a 2013, foi acessado o módulo pesquisador do site da Brapci, delimitando o período de busca para os artigos científicos e em seguida coletando os dados relativos à produção. Após a coleta, buscou-se identificar as temáticas mais publicadas durante o período, para tanto, foram acessados os Diretórios de Pesquisadores em Ciência da Informação na própria base e coletadas as temáticas para posterior organização numa planilha eletrônica que finalmente pudesse gerar os gráficos utilizados. Essa mesma estratégia, serviu para identificar a filiação dos pesquisadores, que foram identificados no mesmo Diretório. Essa identificação completou-se com a busca de informações sobre a situação da pós-graduação em $\mathrm{Cl}$ no Brasil e das posições dos grupos de pesquisa e dos pesquisadores para que pudessem ser visualizados em visão sincrônica.

Posteriormente, com fins de identificação dos bolsistas de produtividade, foi acessado o site do Conselho Nacional de Desenvolvimento Científico e Tecnológico $(\mathrm{CNPq})^{4}$, e utilizada a ferramenta de busca das bolsas em curso no site (), de forma a identificar os pesquisadores bolsistas da área da Ciência da Informação no Brasil.

\section{ANÁLISES E DISCUSSÃO}

A princípio podemos identificar os periódicos indexados pela Brapci, com a exceção da Revista CRB-8 (Quadro 1), inseridos dentro das Ciências Sociais Aplicadas I, de acordo com os critérios das áreas de avaliação da Capes. Os 26 periódicos vigentes estão em ordem decrescente de nota de avaliação conforme os indicadores Qualis correspondentes à Avaliação realizada na área.

periódica brasileira em Ciência da Informação. Atualmente a Brapci disponibiliza referências e resumos de 9673 textos publicados em 37 periódicos nacionais impressos e eletrônicos da área de $\mathrm{Cl}$. Dos periódicos disponíveis, 28 estão ativos e nove são históricos (descontinuados). Devido a essa quantidade e à confiabilidade de seus artigos, ela tem sido considerada ferramenta útil e segura para os pesquisadores. O acesso à Brapci pode ser realizado pelo site: <www.brapci.ufpr.br>.

${ }^{3}$ O WEBQUALIS pode ser acessado pelo site: <www.capes.gov.br/avaliacao/qualis $>$.

${ }^{4}<$ http://plsql1.cnpq.br/divulg/RESULTADO_PQ_102003.curso>. 
Quadro 1 - Qualis dos Periódicos - Outubro 2013

\begin{tabular}{|c|c|}
\hline Título do Periódico & $\begin{array}{l}\text { Estrato Qualis - Ciências Sociais } \\
\text { Aplicadas I }\end{array}$ \\
\hline Perspectivas em Ciência da Informação (Impresso) & A1 \\
\hline Transinformação & A1 \\
\hline Informação \& Sociedade (UFPB. Online) & A1 \\
\hline Ciência da Informação (Impresso) & A2 \\
\hline $\begin{array}{l}\text { Revista Brasileira de Biblioteconomia e } \\
\text { Documentação (Impresso) }\end{array}$ & B1 \\
\hline Encontros Bibli & B1 \\
\hline Datagramazero (Rio de Janeiro) & B1 \\
\hline Em Questão (UFRGS. Impresso) & B1 \\
\hline $\begin{array}{l}\text { Revista Digital de Biblioteconomia e Ciência da } \\
\text { Informação }\end{array}$ & B1 \\
\hline $\begin{array}{l}\text { Revista Ibero-Americana de Ciência da } \\
\text { Informação }\end{array}$ & B1 \\
\hline Perspectivas em Gestão \& Conhecimento & B1 \\
\hline $\begin{array}{l}\text { Tendências da Pesquisa Brasileira em Ciência da } \\
\text { Informação }\end{array}$ & B1 \\
\hline Informação \& Informação (UEL Online) & B2 \\
\hline Revista ACB (Florianópolis) & B2 \\
\hline Comunicação \& Informação (UFG) & B2 \\
\hline Liinc em Revista & $\mathrm{B} 2$ \\
\hline Brazilian Journal of Information Science & B2 \\
\hline Biblos (Rio Grande) & B3 \\
\hline Pontodeacesso (UFBA) & B3 \\
\hline Biblionline (João Pessoa) & B3 \\
\hline InCID: Revista de Ciência da Informação e & B3 \\
\hline
\end{tabular}




\section{Documentação}

Inclusão Social (Impresso)

B4

Arquivística.net

B4

ETD. Educação Temática Digital

B4

Revista CRB-8 Digital

B5

AtoZ: novas práticas em informação e

B5 conhecimento

Fonte: Dados da Pesquisa.

A composição desse quadro descritivo parte do reconhecimento de que as relações de produção científica e as estruturas institucionais estão diretamente relacionadas com os periódicos, suas avaliações e os acontecimentos que mobilizam essa conjuntura, assim como as relações de coexistência entre eles, o crescimento dos programas de pós-graduação, os órgãos de fomento e outras instituições a eles vinculadas. Como defende Bourdieu (2013, p. 153), no campo universitário não há prevalência absoluta de um princípio de dominação, mas "coexistência concorrencial de vários princípios de hierarquização relativamente independentes". E, nesse caso, as relações de coexistência dos periódicos de CI são presididas por uma equilibrada distribuição no espectro dos elementos valorativos do estrato Qualis.

Para representar as temáticas mais recorrentes selecionadas pelos pesquisadores para a realização de seus trabalhos foram identificadas as 18 palavras-chaves de maior incidência indexadas nos artigos dos periódicos, descritas no Gráfico 1. Destacam-se, no período de 1993 a 2013, os termos Ciência da Informação, Biblioteconomia e Gestão da Informação, sugerindo a reflexão sobre campos de formação que se diversificam e, portanto, vêm exigindo o repensar de seus próprios fundamentos. A Internet, foco de atenção resultante de seu papel para a vida contemporânea, vem a seguir entre as preferências temáticas, seguida pelos termos história e responsabilidade social, componentes dos cinco de maior destaque. 
Faces da produção periódica na Ciência da Informação: o processo de legitimação científica e seus componentes

Gráfico 1 - Temáticas mais recorrentes no período

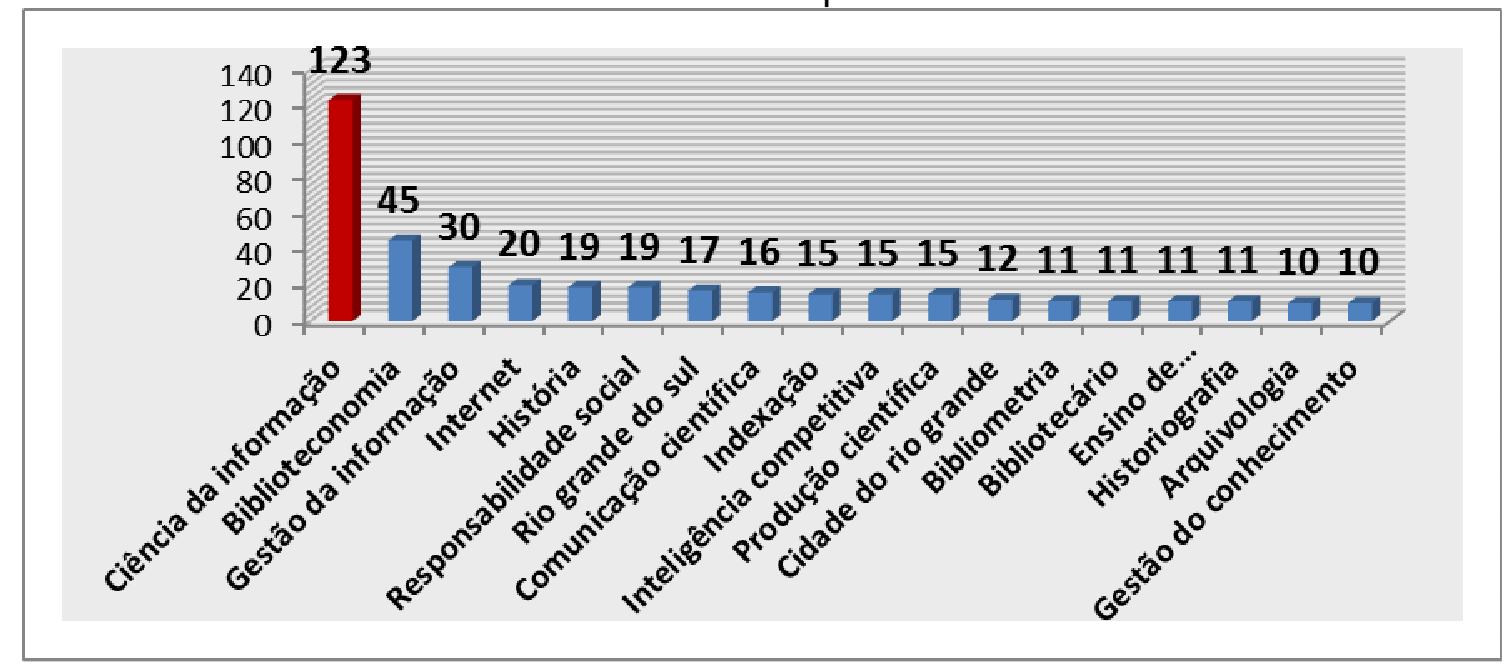

Fonte: Dados da pesquisa.

Em seguida, foram elencados os 15 pesquisadores representativos no período analisado, ou seja, os que mais contribuíram para o crescimento da produção científica na área. Claramente influentes no campo científico que representam, uma vez que contribuem também para os programas em que atuam, esses autores exercem posições de poder relativas ao seu peso, que "depende de todos os tributos de poder que ele possui alhures [...] e de todas as possibilidades de troca que ele pode obter de suas diferentes posições". (BOURDIEU, 2013, 118). (Gráfico 2).

Embora não tenham sido identificados pelos seus nomes os 15 pesquisadores com produção mais expressiva, um terço compreende pesquisadores do CNPq (Senior, 1 ou 2) no período e somente dois deles não são líderes de grupos de pesquisa. 
Faces da produção periódica na Ciência da Informação: o processo de legitimação científica e seus componentes

Gráfico 2 - Pesquisadores mais representativos

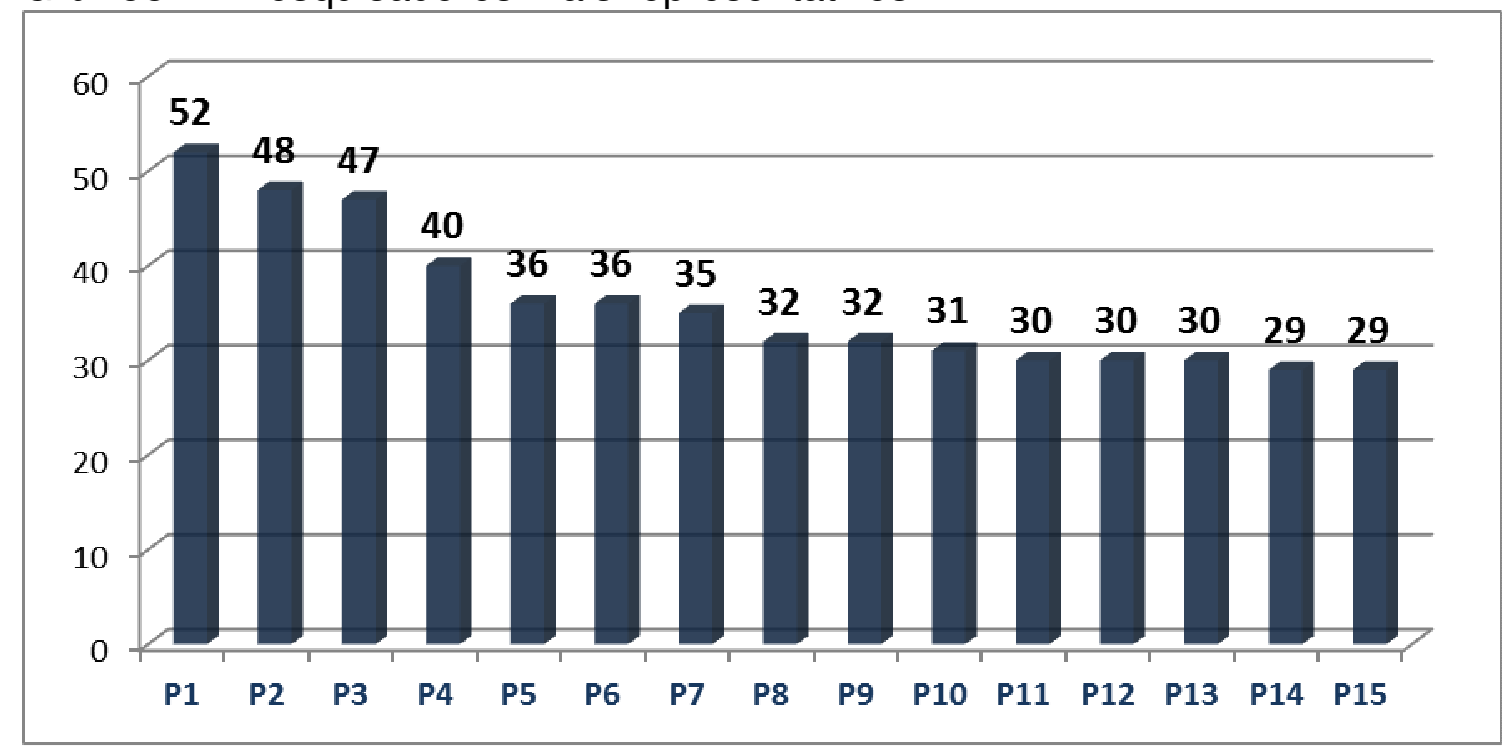

Fonte: Dados da pesquisa.

Para efeito de visualização das instituições às quais esses pesquisadores estão vinculados, buscou-se mapear suas filiações, de modo a configurar institucional e regionalmente essas relações na área. A concentração de sete pesquisadores da região sul, seis da região sudeste e apenas dois da região nordeste é perceptível no Gráfico 3, no qual se definem seis instituições FURG, UFMG, Udesc, Unesp, UFSC e UFPB, cada uma com dois pesquisadores representantes no corpus analisado e outras cinco instituições, com um pesquisador cada uma: UFF, UFPB, UFPR, UEL e Usp. Percebe-se, assim, a concentração dos pesquisadores mais produtivos nas regiões ao Sul e Sudeste do País, enquanto que as regiões Norte e Centro-Oeste não são representadas. Esse fenômeno tem sido estudado por pesquisadores de outras áreas, como ilustra o trabalho de Mendes et al (2010) sobre o perfil dos bolsistas de produtividade científica da área de medicina no Conselho Nacional de Desenvolvimento Científico e Tecnológico, no triênio 20052007. Entre as variáveis estudadas, a instituição de origem mostra que a maioria dos bolsistas, distribuídos por 13 estados da federação, vincula-se aos estados de São Paulo e Rio de Janeiro. 
Faces da produção periódica na Ciência da Informação: o processo de legitimação científica e seus componentes

Gráfico 3 - Filiação dos Pesquisadores

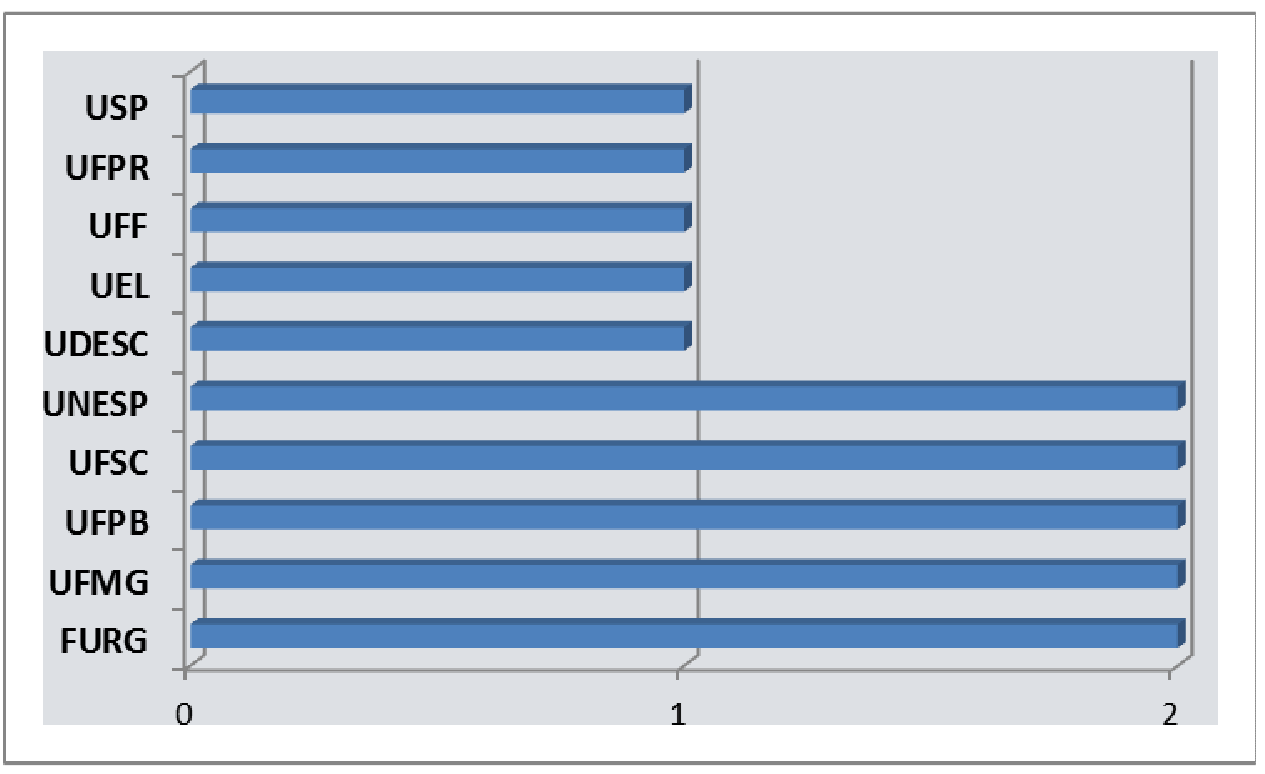

Fonte: Dados da pesquisa.

No Quadro 2, são identificados os pesquisadores mais representados na Brapci atuantes nos programas de pós-graduação em $\mathrm{Cl}$ do Brasil, bolsistas de produtividade e suas filiações institucionais. Embora todos os pesquisadores $\mathrm{CNPq}$ sejam líderes de grupos de pesquisa, nem todos estão entre os mais representados na Brapci, constatação coincidente com a argumentação de Bourdieu (2013, p. 135) sobre a alocação do orçamento-tempo em relação às diferentes espécies de capital, de modo especial "no trabalho de acumulação e de gestão do capital universitário inclusive em seu trabalho 'pessoal', consagrado em grande parte à produção de instrumentos intelectuais que são também instrumentos de poder propriamente universitário, cursos, manuais, dicionários, enciclopédias [...]".

Quadro 2- Bolsistas de Produtividade - outubro 2013

\begin{tabular}{|c|c|c|c|c|}
\hline Nome & Nível & Início & Término & Instituição \\
\hline $\begin{array}{c}\text { Aldo de } \\
\text { Albuquerque } \\
\text { Barreto }\end{array}$ & PQ-SR & $01 / 03 / 2009$ & $28 / 02 / 2017$ & IBICT \\
\hline $\begin{array}{c}\text { Maria Nélida } \\
\text { González de } \\
\text { Gómez }\end{array}$ & PQ-1A & $01 / 03 / 2012$ & $28 / 02 / 2017$ & IBICT \\
\hline
\end{tabular}


Faces da produção periódica na Ciência da Informação: o processo de legitimação científica e seus componentes

\begin{tabular}{|c|c|c|c|c|}
\hline $\begin{array}{l}\text { Regina Maria } \\
\text { Marteleto }\end{array}$ & PQ-1A & 01/03/2010 & $28 / 02 / 2015$ & FIOCRUZ \\
\hline $\begin{array}{l}\text { Suzana Pinheiro } \\
\text { Machado Mueller }\end{array}$ & PQ-1A & 01/03/2011 & 29/02/2016 & UNB \\
\hline $\begin{array}{c}\text { José Augusto } \\
\text { Chaves Guimarães }\end{array}$ & PQ-1B & 01/03/2012 & 29/02/2016 & UNESP \\
\hline $\begin{array}{c}\text { Lena Vania Ribeiro } \\
\text { Pinheiro }\end{array}$ & PQ-1B & 01/03/2012 & 29/02/2016 & IBICT \\
\hline $\begin{array}{c}\text { Rosali Fernandez } \\
\text { de Souza }\end{array}$ & PQ-1B & 01/03/2012 & $29 / 02 / 2016$ & IBICT \\
\hline $\begin{array}{l}\text { Mariângela Spotti } \\
\text { Lopes Fujita }\end{array}$ & PQ-1C & $01 / 03 / 2010$ & $28 / 02 / 2015$ & UNESP \\
\hline $\begin{array}{l}\text { Marilda Lopes } \\
\text { Ginez de Lara }\end{array}$ & PQ-1C & $01 / 03 / 2010$ & $28 / 02 / 2014$ & USP \\
\hline $\begin{array}{l}\text { Leilah Santiago } \\
\text { Bufrem }\end{array}$ & PQ-1D & $01 / 03 / 2013$ & $28 / 02 / 2017$ & UFPE / UNESP \\
\hline $\begin{array}{l}\text { Beatriz Valadares } \\
\text { Cendón }\end{array}$ & PQ-1D & 01/03/2012 & $29 / 02 / 2016$ & UFMG \\
\hline $\begin{array}{l}\text { Gilda Olinto de } \\
\text { Oliveira }\end{array}$ & PQ-1D & $01 / 03 / 2010$ & $28 / 02 / 2014$ & IBICT \\
\hline IcleiaThiesen & PQ-1D & $01 / 03 / 2012$ & $29 / 02 / 2016$ & UNIRIO \\
\hline $\begin{array}{c}\text { Nair } \\
\text { YumikoKobashi }\end{array}$ & PQ-1D & $01 / 03 / 2013$ & 28/02/2017 & USP \\
\hline Sarita Albagli & PQ-1D & $01 / 03 / 2010$ & $28 / 02 / 2014$ & IBICT \\
\hline $\begin{array}{c}\text { Sueli Angelica do } \\
\text { Amaral }\end{array}$ & PQ-1D & $01 / 03 / 2010$ & $28 / 02 / 2014$ & UNB \\
\hline $\begin{array}{l}\text { André Porto } \\
\text { Ancona Lopez }\end{array}$ & PQ-2 & $01 / 03 / 2013$ & $29 / 02 / 2016$ & UNB \\
\hline $\begin{array}{l}\text { Carlos Henrique } \\
\text { Marcondes de } \\
\text { Almeida }\end{array}$ & PQ-2 & 01/03/2011 & $28 / 02 / 2014$ & UFF \\
\hline Edberto Ferneda & PQ-2 & $01 / 03 / 2013$ & $29 / 02 / 2016$ & UNESP \\
\hline $\begin{array}{l}\text { Eduardo Ismael } \\
\text { MurguiaMarañon }\end{array}$ & PQ-2 & $01 / 03 / 2011$ & $28 / 02 / 2014$ & UFF \\
\hline $\begin{array}{c}\text { Ely } \\
\text { FrancinaTannuri de } \\
\text { Oliveira }\end{array}$ & PQ-2 & $01 / 03 / 2011$ & $28 / 02 / 2014$ & UNESP \\
\hline $\begin{array}{c}\text { Evelyn Goyannes } \\
\text { Dill Orrico }\end{array}$ & PQ-2 & 01/03/2013 & $29 / 02 / 2016$ & UNIRIO \\
\hline $\begin{array}{c}\text { Guilherme Ataíde } \\
\text { Dias }\end{array}$ & PQ-2 & $01 / 03 / 2013$ & $29 / 02 / 2016$ & UFPB \\
\hline $\begin{array}{c}\text { Helen de Castro } \\
\text { Silva Casarin }\end{array}$ & PQ-2 & $01 / 03 / 2013$ & $29 / 02 / 2016$ & UNESP \\
\hline Isa Maria Freire & PQ-2 & 01/03/2012 & $28 / 02 / 2015$ & UFPB \\
\hline
\end{tabular}


Faces da produção periódica na Ciência da Informação: o processo de legitimação científica e seus componentes

\begin{tabular}{|c|c|c|c|c|}
\hline $\begin{array}{c}\text { João Batista } \\
\text { Ernesto de Moraes }\end{array}$ & PQ-2 & $01 / 03 / 2012$ & $28 / 02 / 2015$ & UNESP \\
\hline Jose Maria Jardim & PQ-2 & $01 / 03 / 2013$ & $29 / 02 / 2016$ & UNIRIO \\
\hline $\begin{array}{l}\text { Lídia Silva de } \\
\text { Freitas }\end{array}$ & PQ-2 & $01 / 03 / 2013$ & $29 / 02 / 2016$ & UFF \\
\hline $\begin{array}{l}\text { Marco Antônio de } \\
\text { Almeida }\end{array}$ & PQ-2 & $01 / 03 / 2012$ & $28 / 02 / 2015$ & USP \\
\hline $\begin{array}{l}\text { Maria Aparecida } \\
\text { Moura }\end{array}$ & PQ-2 & $01 / 03 / 2013$ & $29 / 02 / 2016$ & UFMG \\
\hline $\begin{array}{l}\text { Maria Cláudia } \\
\text { Cabrini Grácio }\end{array}$ & PQ-2 & $01 / 03 / 2013$ & $29 / 02 / 2016$ & UNESP \\
\hline $\begin{array}{c}\text { Maria Cristina } \\
\text { Piumbato } \\
\text { Innocentini } \\
\text { Hayashi }\end{array}$ & PQ-2 & $01 / 03 / 2012$ & $28 / 02 / 2015$ & UFSCAR \\
\hline $\begin{array}{c}\text { Maria de Fátima } \\
\text { Gonçalves Moreira } \\
\text { Tálamo }\end{array}$ & PQ-2 & $01 / 03 / 2013$ & $29 / 02 / 2016$ & USP \\
\hline $\begin{array}{l}\text { Maria Luiza de } \\
\text { Almeida Campos }\end{array}$ & PQ-2 & $01 / 03 / 2012$ & $28 / 02 / 2015$ & UFF \\
\hline $\begin{array}{c}\text { Marisa } \\
\text { BrascherBasilio } \\
\text { Medeiros }\end{array}$ & PQ-2 & $01 / 03 / 2011$ & $28 / 02 / 2014$ & UNB \\
\hline $\begin{array}{c}\text { Marta Lígia } \\
\text { Pomim Valentim }\end{array}$ & PQ-2 & $01 / 03 / 2013$ & $29 / 02 / 2016$ & UNESP \\
\hline $\begin{array}{l}\text { Miriam Figueiredo } \\
\text { Vieira da Cunha }\end{array}$ & PQ-2 & $01 / 03 / 2011$ & $28 / 02 / 2014$ & UFSC \\
\hline $\begin{array}{l}\text { Nanci Elizabeth } \\
\text { Oddone }\end{array}$ & PQ-2 & $01 / 03 / 2013$ & $29 / 02 / 2016$ & UNIRIO \\
\hline $\begin{array}{l}\text { Plácida Leopoldina } \\
\text { Ventura Amorim } \\
\text { da Costa Santos }\end{array}$ & PQ-2 & $01 / 03 / 2013$ & $29 / 02 / 2016$ & UNESP \\
\hline $\begin{array}{l}\text { Raimundo Nonato } \\
\text { Macedo dos Santos }\end{array}$ & PQ-2 & $01 / 03 / 2011$ & $28 / 02 / 2014$ & UFPE \\
\hline $\begin{array}{l}\text { Rubens Ribeiro } \\
\text { Gonçalves da Silva }\end{array}$ & PQ-2 & $01 / 03 / 2013$ & $29 / 02 / 2016$ & UFBA \\
\hline $\begin{array}{c}\text { Silvana Aparecida } \\
\text { Borsetti Gregorio } \\
\text { Vidotti }\end{array}$ & PQ-2 & $01 / 03 / 2011$ & $28 / 02 / 2014$ & UNESP \\
\hline $\begin{array}{l}\text { Silvana Drumond } \\
\text { Monteiro }\end{array}$ & PQ-2 & $01 / 03 / 2012$ & $28 / 02 / 2015$ & UEL \\
\hline $\begin{array}{c}\text { Vera Lucia Doyle } \\
\text { Louzada de Mattos } \\
\text { Dodebei }\end{array}$ & PQ-2 & $01 / 03 / 2012$ & $28 / 02 / 2015$ & UNIRIO \\
\hline $\begin{array}{l}\text { Virginia Bentes } \\
\text { Pinto }\end{array}$ & PQ-2 & $01 / 03 / 2013$ & $29 / 02 / 2016$ & UFC \\
\hline
\end{tabular}

Fonte: Dados da pesquisa. 
Observamos que as instituições com programas mais antigos, especialmente aqueles com doutorado, abrigam a maioria dos pesquisadores CNPq, o que decorre certamente do tempo de poder, ou seja, da permanência em situação capaz de organizar e estruturar situações de produção mais estáveis e, portanto, com melhores condições de produção.

Compreendemos, entretanto, que esses resultados parciais apenas ilustram o grau de reconhecimento e consagração concedido pelos pares e instituições, uma vez que decorrem das relações de uma estrutura inteira que se interpõe entre o produtor pesquisador e suas ambições mais ou menos legítimas. Os pesquisadores de destaque, considerados os atores dominantes no campo de relações objetivas em que atuam, exercem o poder que lhe é concedido e por sua vez passam a atuar nas instâncias de consagração, alçados a elas graças às suas reconhecidas competências.

Variam as posições e as formas de distinção, mas se estabelecem constantes que validam essas posições relativas, decorrentes de um conjunto de relações temporais que dão sentido à produção científica. Portanto, a progressão dessas posições é de natureza tendencial, mas não determinante.

\section{CONSIDERAÇÕES}

Se a pesquisa como objeto de trabalho é uma realidade em plena expansão e da qual temos participado, as ideias e o tempo mostram que a cada estágio vivenciam-se não somente experiências concretas que deixaram marcas pessoais e coletivas na memória social, mas também processos de institucionalização científica de um campo de conhecimentos em expansão.

Essas reflexões podem ser consideradas síntese de uma tese construída no decorrer de anos de reflexão sobre a pesquisa, a docência e a atuação na formação, qualificação e avaliação de processos e produtos de pesquisa. Seu valor relativo e o dos seus resultados residem nas contribuições que possam oferecer às políticas de produção e comunicação científicas, assim como ao seu autoconhecimento e as necessárias transformações sobre o campo de produção científica em questão, visando o aprimoramento da prática de avaliação e de reconhecimento. É aqui apresentada como novo alvo de interesse e crítica coletivos com o propósito de 
incentivar a reflexão sobre essa prática de análise e suas formas consequentes de produção, reprodução e distinção. Desse modo, ao nos voltarmos às posições concretas, pensamos motivar a prática coletiva da crítica sobre a pesquisa e a produção científica cotidianamente vivida.

A crítica sobre a prática concreta dessas atividades poderá identificar situações e variáveis passíveis de reconhecimento por outras áreas e contextos, com desdobramentos para soluções concretas em processos de avaliação institucional.

A distinção seria, desse modo, um estado diferencial e decorrente da aprovação pelos pares e instituições, diretamente associado à possibilidade de ampliação de ações efetivas e trabalhos publicados pelo intelectual ou pelo grupo.

Isso porque o engessamento de práticas de avaliação, concretizadas em documentos de áreas acadêmicas específicas, por exemplo, pode eventualmente reforçar as preferências por periódicos, editoras ou instituições já consagradas, privilegiando suas possibilidades de seleção e seus quadros, por um processo cumulativo de capital científico. Desse processo, resulta uma discriminação negativa em relação à dialética quantidade qualidade, gerada pelos efeitos da distinção que adquirem pesquisadores, periódicos, editoras e instituições no cenário marcado pelo poder do capital.

Como sugestão para estudos futuros, visualizamos a possibilidade de mapeamento das categorias aqui somente ilustrativas do processo resultante de relações de força, conflitos e contradições entre pesquisadores, instituições e grupos de pesquisa, interesses e discursos, assim como as orientações e tendências de reprodução, distinções ou transformações possíveis nesse campo do conhecimento.

\section{REFERÊNCIAS}

BARRETO, Aldo de Albuquerque. Olhar sobre os 20 anos da Associação Nacional de Pesquisa e Pós-Graduação em Ciência da Informação (Ancib). Pesq. Bras. Ci. Inf., Brasília, v. 2, n. 1, p.3-28, jan./dez. 2009.

BOURDIEU, Pierre. O campo científico. In: Pierre Bourdieu: Sociologia (Cap. 4, p. 122-155). São Paulo: Ática, 1983. 
Faces da produção periódica na Ciência da Informação: o processo de legitimação científica e seus componentes

BOURDIEU, Pierre. A distinção: crítica social do julgamento. São Paulo: EDUSP; Porto Alegre: Zouk, 2007.

BOURDIEU, Pierre. Questões de sociologia. Rio de Janeiro: Marco Zero, 1983.

BOURDIEU, Pierre. La noblesse d'État: grandes écoles et esprit de corps. Paris: Les Éditions de Minuit, 1989.

BOURDIEU, Pierre. A economia das trocas simbólicas. São Paulo: Perspectiva, 1992.

BOURDIEU, Pierre. Razões práticas: sobre a teoria da ação. São Paulo: Papirus, 1996.

BOURDIEU, Pierre. Homo academicus. 2. ed. Florianópolis: Editora UFSC, 2013.

BOURDIEU, Pierre; PASSERON, Jean-Claude. A reprodução. Elementos para uma teoria do sistema de ensino. Petrópolis, R. J.: Vozes, 2008.

CUNHA, Murilo Bastos. IBICT: 51 anos. Ciência da Informação, Brasília, v. 34, n. 1, jan. 2005 .

KANT, Immanuel. Crítica da faculdade do juízo. Rio de Janeiro: Forense Universitária, 2008.

LIMA, Maycke Young de. Coautoria na produção científica do PGGeo/UFRGS: uma análise de redes sociais. Ciência da Informação, Brasília, v. 40, n. 1, p. 38-51, jan./abr. 2011.

MENDES, Patrícia Helena Costa et al. Perfil dos pesquisadores bolsistas de produtividade científica em medicina no CNPq, Brasil. Rev. bras. educ. med., Rio de Janeiro , v. 34, n. 4, dec. 2010.

MURGUIA, Eduardo Ismael; SALES, Rodrigo. CNPq's knowledge area table as a knowledge and power apparatus. In: ISKO (Indian Chapter) and University of Mysore. (Org.). Anais... Categories, contexts and relations in knowledge organization. 1ed.Wurzburg: Ergon Verlag, 2012, v. 13, p. 183-189.

OLIVEIRA, Ely Francina Tannuri de; GRÁCIO, Maria Cláudia Cabrini. A produção científica em Organização e representação do conhecimento no Brasil: uma análise bibliométrica do GT-2 da ANCIB. In: ENCONTRO NACIONAL DE PESQUISA DA ANCIB - ENANCIB, X, João Pessoa, 2009. Anais... João Pessoa: ANCIB, 2009.

OLIVEIRA, Marlene de. Grupos de pesquisa em ciência da informação no Brasil. Tendências da Pesquisa Brasileira em Ciência da Informação, João Pessoa, v. 2, n. 1, p. 38-59, 2009. 
PINTO, Marli Dias de Souza; SANTOS, Raimundo Nonato Macedo dos; BAHIA, Eliana Maria dos Santos. Citation analysis of electronic Arquivística.net journal: an application of bibliometric techniques. Em Questão: Revista da Faculdade de Biblioteconomia e Comunicação da UFRGS, Porto Alegre, v. 15, n. 1, p. 27-42, 2009.

PRADO JUNIOR, Caio. Teoria marxista do conhecimento e método dialético materialista. Edição eletrônica Ridendo Castigat Mores, 2001. Disponível em: $<$ http://www.ebooksbrasil.org/adobeebook/caio.pdf>.

SANTOS, Raimundo Nonato Macedo dos. Produção científica: por que medir? o que medir? Revista Digital de Biblioteconomia \& Ciência da Informação, Campinas, v. 1, n. 1, p. 22-38, jul./dez. 2003.

SOUZA, Elisabete Gonçalves. Sociedade da informação e reestruturação produtiva: crítica à dimensão utilitarista do conhecimento. Transinformação, Campinas, v. 23, n. 3, p. 219-226, 2011.

VAISMAN, Ester; FORTES, Ronaldo Vielmi. A categoria da reprodução: Lukács, Althusser e Bourdieu \&Passeron. In: V ENCONTRO BRASILEIRO DE EDUCAÇÃO E MARXISMO: EDUCAÇÃO E EMANCIPAÇÃO HUMANA, 3, 2011.

Anais...Florianópolis: UFSC, 2011. v. 2.

WHITLEY, Richard. Cognitive and social institutionalization of scientific specialities and research áreas. In: . (Ed.). Social processes of scientific development. London: Routledge and Kegan, 1974. p. 69-95.

Title

Aspects of the periodical production in information science: the process of scientific legitimation and its components

\section{Abstract}

Introduction: This paper analyzes the production by a representative group of researchers in the field of Information Science in Brazil, from 1993 to 2003. In doing so, it highlights the relationships presented in the process of legitimation of the field and compares them to the theoretical aspects concerning the processes of production and reproduction in scientific literature. Furthermore, it establishes a comparison to the distinction that the community attributes to certain researchers and institutions.

Objectives: It aims to analyze the characteristics of this production and their relationships, in the indexed literature on Base Reference Data Journal Articles in Information Science to highpoint the processes of production and reproduction in scientific literature.

Methodology: Based on bibliometric settings, it analyzes the characteristics of this production and the relationships presented by it, as well as providing an analysis on how its 
components are emphasized. Furthermore, it establishes a comparison between production and the distinction that the community attributes to certain researchers and institutions.

Results: It considers the expansion of competitive elements and its performance of academics and researchers, resulting in forms of social reproduction and distinction in the scientific field. The paper discusses the process of legitimization accomplished through the legitimizing entities in the community of IS, explaining some aspects related to the consequences of this distinction process and the relationships established within the social group affecting the way it produces.

Conclusion: The reflections on the three critical aspects of the process of scientific research, the production, reproduction and distinction, present factors which highlight convergences for their accomplishment.

Key words: Scientific production. Reproduction. Distinction. Information science

\section{Título}

Aspectos de la producción periódica en Ciencia de la Información: el proceso de legitimación científica y sus componentes

\section{Resumen}

Introducción: Presenta resultados de investigación sobre la producción científica registrada en Ciencia de la Información a partir de datos de incidencia empírica obtenidos en la investigación bibliométrica sobre un corpus de la literatura del área en Brasil, elaborado por un grupo de investigadores en el período de 1993 a 2013, destacando las relaciones que se presentan en el proceso de consagración y legitimación y comparándolos con los aspectos teóricos de los procesos de producción y reproducción de la literatura científica, así como la distinción otorgada por investigadores e instituciones de la comunidad.

Objetivo: Analiza mediante contribuciones bibliométricas, las características y las relaciones que esta producción presenta y el modo como se destacan sus componentes.

Metodología: Identifica artículos de periódicos científicos de 15 investigadores con producción significativa desde 1993 hasta 2013, basado en una encuesta bibliométrica de las revistas existentes indexadas en Base de Dados de Artigos de Periódicos em Ciência da Informação (Brapci). Analiza los artículos científicos, identificando sus problemas y relacionando sus autores a las instituciones y posiciones académicas, representando esos datos en hojas de cálculo y gráficos organizados a través de los cuales se visualizan las relaciones y posiciones de los autores y sus puestos como investigadores del CNPq. Se completa la identificación con la búsqueda de información sobre el estado de graduado en $\mathrm{Cl}$ en Brasil y las posiciones de los grupos de investigación e investigadores para una vista del contexto sincrónico.

Resultados: Como resultado del análisis de los datos obtenidos de la investigación, señala que un tercio de los autores es parte de la lista de investigadores del CNPq y de las instituciones más importantes en el ámbito de la $\mathrm{Cl}$, cuyos programas son más distinguidos y tienen doctorado, además de contar con la más importante parcela de los investigadores del CNPq.

Conclusiones: Apunta que la legitimación y la distinción dependen del tiempo de poder, es decir, de la presencia del investigador en situación que lo capacita a organizar y estructurar las condiciones de producción más estables y, por lo tanto, con más posibilidades de éxito. 
Faces da produção periódica na Ciência da Informação: o processo de legitimação científica e seus componentes

Concluye que los tres aspectos críticos del proceso de la investigación científica, la producción, la reproducción y la distinción, presentan singularidades que ilustran la convergencia hasta el proceso de legitimación de instancias de consagración en la comunidad de las experiencias del campo de la producción científica.

Palabras clave: Producción científica. Reproducción. Distinción. Ciencia de la Información.

Recebido em: 24.02.2014

Aceito em: 19.12.2014 